Medical students' views on necropsies

I read the article by Benbow with interest.' In my hospital we try to anticipate some of the problems likely to arise in this area by circulating an information sheet on necropsies to all medical students. This has been so useful that it has been adapted for a wide range of people who may need to view a necropsy as part of their training-from student nurses and doctors, hospital administrators, paramedical staff (ambulance personnel), and even the new members of the hospital chaplaincy, who may be asked to counsel families from whom permission for necropsy has been requested.

A copy of the information sheet is available on request from the address below.

HE EMSON

Department of Pathology, Royal University Hospital, Saskatoon, $S K$,

Canada S7N OXO

1 Benbow EW. Medical students' views on necropsies. J Clin Pathol 1990;43:969-76.

\section{AgNOR staining in normal bone marrow cells}

We were pleased to read that in their article Nikicicz and Norback emphasised the importance of the differential morphological expression of AgNORs using their own classification. ' Yet their system, with eight types of structures and five types of configurations, seems very complicated to us. For a statistical evaluation a great number of data would be necessary. Moreover, we think that some AgNOR structures could be erroneously classified because of an inclination of their main axis in relation to the surface of the slide. That could falsely increase the number of regular blebs and reduce the number of irregular blebs. A complex classification system could also raise the intra- and interobserver variability.

We have also recently studied AgNORs in normal bone marrow cells ${ }^{2}$ differentiating only the following groups: clusters of NORs within a matrix; small dots within the nucleoplasm; and rounded argyrophilic structures corresponding to a small nucleolus. ${ }^{3}$ The intra- and interobserver variability were less than $10 \%$. A characteristic pattern of clusters or dots, or both, could be seen in each cell type. Clusters were only present in proliferating cells. The number of dots was lowest in the most immature cells, increased initially with maturation, but decreased as the final maturation to the end stage cell took place. Thus our quantitative analysis suggests a difference between dots and clusters also on a physiological level.

Hansen and Østergård proposed another classification system that is principally based on the differentiation in dots and clusters. ${ }^{4}$ Interestingly, it was noted that dots predominated in hyperplastic prostatic tissue; the subtypes of clusters (with one exception) were only observed in intraepithelial neoplasia and carcinoma of the prostate.

In conclusion, we feel that the validity of a morphological classification system should be measured by its physiological or pathophysiological importance.
K METZE Department of Pathology, State University of Campinas 13081, Campinas-SP, Brazi I LORAND-METZE Division of Haematology, Department of Internal Medicine,
State University of Campinas

1 Nikicicz EP, Norback DH. Argyrophilic

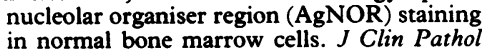
in normal bone

2 Grotto HZW, Lorand-Metze I, Metze K. Nucleolar organizer regions in normal hematopoesis: relationship to cellular proliferation and maturation. Nouv Rev Hematol (in press).

3 Crocker J, Boldy DAR, Egan MJ. How should we count AgNORs? Proposals for a standardized approach. J Pathol 1989;158:185-8

4 Hansen AB, Østergård B. Nucleolar organiser regions in hyperplastic and neoplastic prostatic tissue. Virchows Arch (Pathol Anat) 1990;417:9-13.

\section{Drs Nikicicz and Norback comment:}

We are pleased that our article has stimulated interest and thank Drs Metze and LorandMetze for their comments.

Our system of AgNOR structures and the non-AgNOR staining features allows recognition of a wide spectrum of patterns and characterises all types of normal bone marrow cells at various levels of maturation.

In the study we used air-dried smears of bone marrow aspirates. This preparation flattens the cells on the coverslip, allowing maximum spreading and good bidimensional assessment of cellular features. The structural variability due to orientation of the cell is therefore minimal compared to the variability in preparations of immediately fixed cells or histological sections. The systems of describing AgNORs cited by Drs Metze and Lorand-Metze apply to histological sections and take into account the smaller AgNOR subunits within larger AgNOR clusters or structures. In our preparations of whole cells, subunits were not well visualised. Instead, we incorporated the shape of AgNOR structures into a system which also uses size and number of the structures.

We agree that further studies of AgNORs of bone marrow cells in various physiological and pathological conditions should be the next step. The completion of these studies may indeed allow modifications of the system to describe such cells.

\section{BOOK REVIEWS}

Clinical Gynaecological Oncology. 2nd ed. Ed JH Shepheard, JM Monaghan. (Pp 479; £59.50.) Blackwells. 1990. ISBN 0-632-02733-9.

This is the second edition of a book that has become a standard text for clinicians engaged in this gynaecological subspeciality. It now has 16 contributors, all of whom are from the United Kingdom, and provides in its 19 chapters a useful, comprehensive, and up to date review of this rapidly developing subject from a British viewpoint. Topics covered include the epidemiology and aetiology of cancers of the female genital tract; pathology and management of CIN, VAIN, and VIN; pathology and management of cancer of the cervix, uterine corpus, vulva, fallopian tube and ovary; trophoblastic disease; malignant disease of the genital organs in childhood; cancer complicating pregnancy; radiotherapy of the cervix, uterine corpus and ovary; nutritional support in gynaecological cancer and care of the terminally ill.

The book is well produced and illustrated, easy to read, and each chapter includes a well chosen and generous list of references to published work. Although it is intended primarily for gynaecologists, the emphasis placed throughout on the multidisciplinary approach to patient diagnosis and management should serve to widen its appeal to include all clinicians involved in gynaecological oncology. I expect the book to become essential reading for the MRCOG examination and would warmly recommend it to all pathologists with an interest in this field.

AJ ROBERTSON

Management of Blood Transfusion Services. Ed SR Hollan, W Wagstaff, J Leikola, F Lothe. (Pp 229; Sw.fr 41.) World Health Organisation. 1990. ISBN 924 1544066

The arrival of this book reflects the recognition by the WHO that blood transfusion has an essential role in developing health care services. This led to a resolve to give assistance to countries to establish their own transfusion services along well tried and secure principles.

This book, comprising 18 chapters contributed by an international panel of experts, serves admirably in this aim. The coverage is well planned with little evidence of overlap or conflict of approach in the chapters. It is clear and well written, comprehensively covering all aspects from the design and planning stages through to choice and commissioning of equipment, establishing operating procedures, recruitment and management of staff, financial management and quality control. Further chapters cover donor recruitment, projection of national blood needs, transmissible infections and educational programmes. A helpful section describes the role of the various international organisations concerned with transfusion.

A very minor criticism relates to a potential confusion in the use of quality control to embrace what is currently covered by the more comprehensive term quality assurance. In vivo recovery measurements are recommended as an important aspect of quality control of blood components-a statement which is theoretically true but which in practice is undermined by the variability of individual clinical settings. In practice, quality assurance of the preparative procedure and appropriate end product laboratory testing are to be emphasised.

The book is primarily directed towards helping the establishment of a modern transfusion service from more humble beginnings and I know of no other single source that would be as useful. The book would also be valuable reading for specialists already working in highly developed sophisticated services as it covers many rather basic principles which could easily be overlooked. It is only to be expected that much of the advice is by way of illustration and will not correspond exactly with particular local requirements laid down 